Acta Poetica 31-2

JULIO-DICIEMBRE

$2010(55-85)$

\title{
Nos-otros: los 70 en Tojolabal. Dialógos con Carlos Lenkersdorf sobre la traducción bíblica
}

\author{
Silvana Rabinovich \\ Renato Huarte Cuéllar
}

La traducción del Nuevo Testamento al tojolabal fue un esfuerzo colectivo en donde participaron una pluralidad de voces. Carlos Lenkersdorf fue parte de esta experiencia. En este diálogo con uno de los especialistas en lengua y filosofía maya-tojolabal, entre sus textos y una serie de preguntas, se pone de manifiesto las implicaciones que tiene la traducción entre dos lenguas, especialmente en los textos bíblicos. La visión desde el tojolabal resalta las profundas raíces sociales, filosóficas, cosmológicas, etc., que el Evangelio tiene y puede significar no solo para los tojolabales, sino para cualquier lector atento de las Escrituras.

PAlabras Clave: tojolabal, Biblia, traducción.

Translating the New Testament into tojolabal was a collective effort in which many voices participated. Carlos Lenkersdorf was part of that experience. In this dialogue with one of the specialists in tojolabal language and philosophy, among his texts and a series of questions, several aspects of translation between two languages, specifically in the biblical texts, are presented. The tojolabal perspective on the Gospels highlights the deep social, philosophical, cosmological, etc. roots not only for tojolabal readers of the Bible, but also for any attentive reader of the biblical scriptures.

KEY Words: tojolabal, Bible, translation 
Fecha de recepción: 15 de febrero de 2010. Fecha de aceptación: 7 de abril de 2010. 
Silvana Rabinovich

Instituto de Investigaciones Filológicas

Universidad Nacional Autónoma de México

Renato Huarte Cuéllar

Facultad de Filosofía y Letras

Universidad Nacional Autónoma de México

\section{Nos-otros: los 70 en Tojolabal. Diálogos con Carlos Lenkersdorf sobre la traducción bíblica}

\section{Introducción}

Carlos Lenkersdorf vivió con los tojolabales ${ }^{1}$ en sus comunidades y aprendió de ellos después de haber estudiado filosofía en la Universidad Nacional Autónoma de México. Ha escrito muchos libros sobre la lengua y cultura de este pueblo maya. Hasta el día de hoy continúa su labor dando clases de filosofía maya-tojolabal en la Facultad de Filosofía y Letras de la Universidad Nacional Autónoma de México. Él mismo narra que los tojolabales han sido sus maestros. En un país en donde los indígenas, junto con su pensamiento, lengua y cosmovisión, han

${ }^{1}$ Desde 1973 tuvo contacto con distintas comunidades tojolabales con quienes vivió por distintos períodos. Aprendió la lengua y les ayudó a sistematizarla. Aprendió su cultura y cosmovisión y desde entonces se ha encargado de transmitirla. 
sido relegados, labores como la del "hermano Carlos" — como lo llaman los propios tojolabales - nos hacen aproximarnos a la filosofía de los pueblos originarios de América desde otra perspectiva.

Podemos partir de la idea de que las lenguas son visiones de mundo en tanto determinan nuestra forma de pensar y de actuar. $^{2}$ Desde esta perspectiva no es lo mismo tener una visión desde el "yo", privilegiado por las lenguas como el griego, el español, el alemán y demás lenguas indoeuropeas, que otras visiones como el "nosotros" $(-t i k)^{3}$ del tojolabal u otras lenguas mayenses.

Hablar desde la perspectiva "nosótrica"4 tiene implicaciones en la vida diaria y en la forma de enfrentar los retos cotidianos y las aspiraciones y formas de ver el mundo. Tanto en lo político, lo económico, lo educativo, lo legal, lo religioso, entre muchos otros aspectos, pensar desde el "nosotros" permite aproximarnos a todas las actividades humanas desde una armonía de voces en donde se privilegia el acuerdo como consenso y "equilibrio" (lajan lajan) de las diferencias entre los miembros de un grupo.

Con esto, experiencias como la de los tojolabales nos permiten revisar nuestros propios pensamientos, costumbres y filosofía. La filosofía maya-tojolabal (ju'un $)^{5}$ nos permite ver a los notojolabales lo que somos y hacemos desde otra perspectiva. Por ejemplo, en tojolabal existen las palabras 'abal y $k$ 'umal. Por un lado, existe lo que decimos ( $k^{\prime}$ umal) y, por otro, lo que escucha-

${ }^{2}$ Cfr. Lenkersdorf, "Otra lengua, otra lógica”, 101-109.

${ }^{3}$ Cfr. Lenkersdorf. "La lengua tik", 23-35. Cabe aclarar que en este trabajo aparecerán entre paréntesis, en negritas o en cursivas las voces tojolabales, según sea el caso para distinguirlas.

${ }^{4}$ Este neologismo ha sido aplicado por Carlos Lenkersdorf a una perspectiva lingüística y cultural desde una lengua como el tojolabal que parte del "nosotros" y no del "yo" como otras lenguas.

${ }^{5}$ El término ju'un hace referencia a la filosofía, pero también a leer y escribir. También refiere a un papel, un libro o cualquier escrito. 
mos ('abal). Su propia lengua, por las palabras que la componen (el tojol'abal) es la lengua escuchada. Por esto decimos que son un pueblo que sabe escuchar (Lenkersdorf, Aprender a escuchar, 165).

El presente artículo trata de la experiencia de traducir la Biblia al tojolabal, además de algunas de sus implicaciones. Busca también presentar un diálogo en donde se incluyan fragmentos de textos escritos por Carlos Lenkersdorf acerca del tema comentado que serán presentados en letra de menor tamaño con sangría. Además se incorporarán pasajes de la entrevista realizada por los autores el 12 de diciembre de 2009. El diálogo será presentado con guiones: en cursivas nuestras preguntas y en letra regular las respuestas de Carlos Lenkersdorf. Las referencias a cada texto se harán al final de cada fragmento.

\section{La traducción de la Biblia al tojolabal}

Cinco años se invirtieron para realizar la obra en la cual participamos setenta traductores, nombrados por nuestras comunidades. Por ello afirmamos que el proyecto expresa la voluntad del mismo pueblo tojolabal. Los traductores venimos de 25 colonias y de tres municipios chiapanecos donde vivimos la mayoría de los tojolabales. No hay que olvidar el aporte de la voz de la mujer muy importante y apreciada. La traducción, pues, refleja el idioma tojolabal como se emplea en los Altos de Chiapas y no se reduce al habla de uno o dos ejidos. Muchas traducciones, de la Biblia y de otros libros, se caracterizan por esa reducción del idioma a pocos hablantes o a grupos limitados por dialectos o clases sociales. La participación de numerosas personas en la producción de libros es de mayor importancia en nuestro contexto donde los documentos antiguos se destruyeron o perdieron y, por 500 años, se han elaborado pocos testimonios escritos. Además, tenemos que tomar en cuenta la importancia del consenso del grupo y del nosotros en el ambiente tojola- 
bal. Estos puntos mencionados representan rasgos característicos del pueblo tojolabal, de nuestra cultura y sociedad. [...] Estamos inculturando el evangelio a la cultura tojolabal sin negarla, y de este modo decimos que estamos produciendo un encuentro entre el evangelio y la cultura o cosmovisión tojolabal (Lenkersdorf, "Hermanos lectores", 5).

-Visto desde afuera, ¿cómo se manifiesta la diferencia en un diálogo en el que prevalece la escucha a la palabra dicha? ¿Hay distintas formas de organizarse para dar la palabra. Hay quien levanta la mano, hay quien pasa un objeto? ¿Cómo se da eso cuando lo primero es la escucha? ¿Cómo se juegan los silencios? Otra pregunta concierne a lo político. La palabra que circula es política. ¿Cómo se ve de afuera? ¿Cómo circulan los silencios?

- Te voy a contestar con un ejemplo que tuvimos una vez en nuestro grupo. Éramos unas diez o quince personas y surgió un problema. Había tojolabales y nosotros. Entonces un tojolabal comentó: "Vamos a resolverlo a la manera tojolabal". Formamos un círculo y lo discutimos. De esta manera habló José, habló Martín, etc. y también Marta y Luisa, etc. Llegó el turno a Marta y ella dijo. "Yo pienso igual que Luisa". El coordinador le contestó: "Mira, todos escuchamos la voz, la opinión de Luisa. Lo que nos interesa es lo que dice tu corazón". Entonces la obligó: "Tienes que hablar lo que dice tu corazón porque el consenso solamente se puede formar de una voz unánime de todo el conjunto. Entonces todos tienen que hablar y el grupo tiene que discutir cómo formará un consenso entre las opiniones diferentes".

- Lo que se acalla no apaga las diferencias. Las diferencias siguen estando pero prevalece lo que es común sin tachar lo diferente.

- De entre muchas opiniones hay que formar un consenso.

- El consenso de ninguna forma va a imponerse sobre el corazón. 
- No, todo el grupo tiene que participar para formar el consenso entre las opiniones diferentes. Y si no se llega al consenso, entonces no puede terminar la discusión. Eso lo he vivido varias veces. En grupos de doscientas, trescientas personas es más complicado, de diferentes comunidades. Una vez, estaba una comunidad que envió a su representante. Cada comunidad antes conocía el problema y formaron el consenso entre sí. Los delegados lo trajeron a la reunión de todos. Una comunidad no estaba de acuerdo y lo manifestaron. Primero el grupo dijo: "Vamos a discutir entre todos para ver". Los representantes de la comunidad disidente dijeron: "Nosotros trajimos el consenso de nuestra comunidad. No podemos aquí ponerlo a discusión sino que tenemos que regresar, informar a nuestra comunidad lo que es el consenso de los demás y a ver qué es lo que nosotros pasamos y es eso lo que vamos a discutir. En la próxima reunión vamos a hablarlo". Y así se hizo. Para los tojolabales no importa que inmediatamente se llegue al acuerdo. Tenemos tiempo. Hasta la siguiente reunión se tomará la decisión, que puede ser en quince días, en un mes, en una semana. Es importante que la otra comunidad también pueda dar su opinión sobre lo que los demás piensan.

La traducción que presentamos no es producto de alguna gente importada desde fuera que aprendió el idioma. Tampoco es el resultado de unos dos o tres traductores del pueblo, seleccionados por especialistas. Tampoco se trata de voluntarios. Nos parece muy instructivo el hecho de que setenta traductores participamos para llevar a cabo el trabajo. Los mismos setenta representamos la voluntad de nuestro pueblo, porque se nos eligió por las comunidades con el encargo de traducir el Nuevo Testamento para que sirviera a los tojolabales. ¿No debemos concluir que este libro manifiesta la voz y voluntad del pueblo? No es la voz del especialista, biblista, teólogo ni de otra persona, por la autoridad que tenga, pero que no forma parte del pueblo. Por eso, con razón la traducción se puede llamar la versión 
de los Setenta en Tojolabal. Para la primera versión de los Setenta del Antiguo Testamento, hace ya más de dos mil años, el punto de partida fue el texto hebreo con el fin de producir una Biblia para la gente de habla griega. Nosotros, en cambio, para el Nuevo Testamento, partimos del griego para elaborar la versión tojolabal de la Biblia ${ }^{6}$. Los primeros setenta tradujeron la Biblia que hoy día llamamos Antiguo Testamento. Hoy día traducimos la segunda parte de la Biblia, el Nuevo Testamento, que en aquel entonces ni existía. Esperamos que un día se tendrá toda la Biblia en tojolabal según la misma voluntad del pueblo (Lenkersdorf, "Hermanos lectores", 6-7).

- Has comentado sobre la traducción de la Biblia al tojolabal, pero no has comentado sobre esta cuestión de la comunidad y el consenso. ¿Cómo se llegó al consenso en la traducción?

- Los traductores eran nombrados por las comunidades y no siempre eran los mismos. Muy a menudo eran otros. Pero, tenían que presentar lo que tradujimos en la reunión de nosotros y la comunidad tenía que aprobarlo o rechazarlo o hacerle correcciones. A la siguiente reunión vinieron otros traductores pero trajeron las correcciones que habían realizado los traductores anteriores y entonces ahí se decidía si se integraban las traducciones o no. Así funcionaba. Cada vez, al principio de la reunión, veíamos las correcciones. En la mayoría de los casos no había problemas. De vez en cuando sí. Por cinco años trabajamos en eso. Entonces se discutieron las correcciones de las comunidades si es que las había. Raras veces hubo que corregir algo. Para integrar las opiniones se escuchaba a los representantes que eran de las comunidades. Se escuchaba de esta manera la traducción que habíamos hecho. En el grupo tal vez eran diez o quince traductores que cada vez se mutaban.

\footnotetext{
${ }^{6}$ Usamos The Greek New Testament (El Nuevo Testamento Griego) editado por Kart Aland y otros, Stuttgart, Sociedad Bíblica Alemana, $3^{\text {a }}$ edición, 1983.
} 
— ¿Por qué traducir la Biblia al tojolabal?

- Porque ellos lo quisieron.

- ¿Ellos lo pidieron?

- Ellos lo pidieron y don Samuel también. Entonces me habló don Samuel Ruiz: "Oye Carlos, ¿no puedes ayudarnos a traducir?" Yo le dije: "No muy quiero. Pero si tú lo pides y las comunidades también, entonces, ¿qué me queda, verdad?"

La participación de tantos traductores, elegidos por sus comunidades para trabajar conforme al consenso o acuerdo de ellas representa el primer paso de inculturación del evangelio. La comunidad de consenso, abarcando la región tojolabal, tomó el acuerdo que se produjera esta traducción, testimonio de dicha voluntad. En este sentido otras traducciones no la pueden igualar, aunque se hayan hecho por personas muy expertas (Lenkersdorf, "Hermanos lectores", 7-8).

- Pero en esta perspectiva nosótrica aún hay cosas que no se entienden. Inclusive hubo una "corrección de estilo" en el libro Aprender a escuchar en donde no está presente esta forma nosótrica.

- En la página 140 dice: "Jesús dijo a sus discípulos durante la celebración de la Pascua: 'Uno de ustedes me entregará (tracionará)'. Escucharon y entendieron el texto los tojolabales y lo tradujeron: 'Uno de ustedes me traicionarán' y el texto dice "traicionará"”.

Les pregunté a los traductores qué opinaban en torno a ese fragmento. Y entonces, nos lo dijeron: "Los traidores son todos corresponsables".

- Entonces, ¿no tendría que ser "uno de nosotros”?

- No, no. "Uno de ustedes". Ahí el grupo predomina. Si es nosotros o ustedes, da igual. Es el grupo el que cuenta. Hay el mismo error en la página 145. Porque tradujeron: uno de ustedes me traicionará(n) (Lenkersdorf, Aprender a escuchar, 145). 
Ahí entre los tojolabales el nosotros y también el grupo predomina y no el individuo. No era solamente el traidor. No era solo Judas, sino todo el grupo $\operatorname{son}^{7}$ corresponsables.

La cohesión grupal es más fuerte que la acción de un solo miembro del grupo. La cohesión grupal sigue vigente. La acción individual no es capaz de disolver la vinculación. En español, en cambio, la cohesión carece de la misma fuerza y, por eso, el individuo, por el comportamiento diferente, se convierte en sujeto. Este individuo es el atractor que se apodera del accionar. De esta manera, sintácticamente, se manifiestan diferentes perspectivas. Por un lado, el grupo puede expresarse en tres formas, el de nosotros, el de ustedes/vosotros y el de ellos. En tojolabal cada grupo es capaz de mantener la cohesión entre todos los componentes del conjunto grupal. Cada grupo representa un atractor fuerte. Por otro lado, en español, el individuo diferente atrae la acción hacia sí mismo y, de esta manera, rompe la fuerza de cohesión de cualquier tipo de grupo (Lenkersdorf, Filosofar en clave tojolabal, 176).

- Bueno, y al final del libro está el pasaje sobre Pedro. Entonces, ahí se está contando una historia.

Ahora bien, al escuchar las palabras de Jesús, los discípulos le preguntan uno tras otros: “¿No lo soy yo?” (Marcos 14:19), es decir, ¿no soy yo el traidor? La pregunta señala que no saben quién lo traicionará, ni siquiera se conocen a sí mismos si son capaces de hacerlo. El escuchar las palabras de Jesús indica que al escuchar podemos percibir realidades desconocidas. Nos pueden sacudir profundamente. Según el texto del evangelio, Jesús habla según las reglas del griego, lengua de una cosmovisión no nosótrica. El traidor es uno del grupo quien es el responsable. Los tojolabales, en cambio, entienden las palabras conforme a su cosmovisión. Uno hace la traición que, sin embargo, hace al grupo corresponsable.

${ }^{7}$ Se decidió mantener el plural empleado por Carlos Lenkersdorf por el sentido mismo de la frase. 
Al terminar la celebración salen de la comida y Jesús les dice: “Todos van a tropezar (desertar)", pero Pedro y los demás discípulos lo niegan con palabras fuertes. Jesús le responde a Pedro que lo negará la misma noche antes de que cante el gallo (Marcos 14:27-31).

El diálogo entre Jesús y los discípulos señala con claridad la reacción de los escuchadores. Se escucha lo que no se sabe, ni se imagina, lo que el escuchador ignora en cuanto a sí mismo. El escuchar es revelador respecto a la realidad y al escuchador mismo. Se oye lo que no se sabe, ni de sí mismo. Por eso, provoca, desconcierta, irrita e indigna al escuchador. Se pueden producir todas estas reacciones. Por tanto, el escuchar es inquietante y se entiende la razón porqué a menudo no se quiere escuchar, porque nos hace inseguros y nos hace dudar de nosotros mismos. Tenemos que agregar lo que el diálogo implica. Si también la autoridad es corresponsable, no sólo va a negarlo, sino que defenderá con fuerza para castigar a quien lo declara responsable. Lo va a declarar como responsable estorbador de la paz social. Todas estas formas de disidencia social son modificaciones de la respuesta de Pedro: la pregunta de los ignorantes, ¿no lo soy yo? Pedro lo niega rotundamente y, más tarde niega conocer a Jesús (Marcos 14: 66-72) (Lenkersdorf, Aprender a escuchar, 142-143).

- ¿Pedro hizo bien o hizo mal al decir "No conozco a ese tipo, a Jesús" cuando le preguntaron en el patio del sumo sacerdote? Con un grupo de centroamericanos en los ochenta, recuerdo que algo sucedió. Era el tiempo cuando en Guatemala y El Salvador había guerrilla. Y había también un grupo muy peligroso. Entonces, cuando te preguntan, como aquí también, cuando la policía pregunta: “¿Tú conoces a fulano o mengano?” Lo niegas. Si lo conoces, lo apresarán. Si tú dices, te llevan y también van a llevar a tus amigos. Entonces, la decisión ahí estaba divida en el grupo. Estábamos los centroamericanos, un pastor de Estados Unidos y yo. Entonces, los centroamericanos dijeron que hizo bien porque conocían la situación cuan- 
do en tu país ocurre eso. Bueno, ahora también con la policía que tenemos.

El hecho que Pedro negó conocer a Jesús produjo una discusión muy animada en una reunión en Centroamérica en los años ochenta, del siglo pasado. Fueron los años de la insurrección en Guatemala y El Salvador. Creemos que fue en Costa Rica donde estuvimos por invitación de pastores luteranos, uno de EU y los demás de Guatemala. Surgió la pregunta si Pedro respondió bien o mal cuando negó que conociera a Jesús. Los centroamericanos respondieron de manera unánime que respondió bien, porque en una situación de guerra civil entre defensores de las autoridades y disidentes, se cambian las reglas comúnmente reconocidas, de decir la verdad o de no mentir. A los disidentes el pueblo reconoce como los defensores de la patria en una situación de crisis nacional. Por eso, si se dice la verdad a las autoridades y sus representantes, no sólo se expone uno a los castigos, posiblemente torturas y la muerte, sino también se expone a peligros parecidos a [a los que padecieron] nuestros compañeros y hermanos, tanto mujeres como hombres. Son personas de cuya vida somos corresponsables.

Al escuchar las palabras de los centroamericanos, se enojó profundamente el pastor de EU. Enfatizó que, como cristianos tenemos que decir la verdad sin considerar las consecuencias posibles. No convenció a los centroamericanos. Cada uno defendió y explicó su respuesta y los guatemaltecos dijeron que la defensa de la vida de los hermanos es más importante que la verdad que no defiende la vida sino un principio. Pero el estadounidense defendió el valor de la verdad como norma cristiana por encima de las demás normas. No se produjo ningún acuerdo.

El evangelio mismo, según nos pareció, opta por la posición de la verdad como norma, por eso dice que Pedro lloró al acordarse de las palabras de Jesús que lo iba a negar. Los centroamericanos, en cambio, conocedores de la situación en sus países, [que] habían experimentado las desapariciones y asesinatos de familiares, no pudieron aceptar la defensa de la 
norma de la verdad a como dé lugar (Lenkersdorf, Aprender a escuchar, 143-144).

— Entonces, dijeron: "Pedro hizo bien porque estaba no solo en peligro su vida, sino la de sus hermanos y hermanas". Así dijeron los centroamericanos. Entonces, el estadounidense agregó: "No. Como cristianos siempre debemos decir la verdad". Entonces yo dije: "Vamos a ver el texto otra vez en griego". Y ahí sí dice: "Uno de ustedes me va a traicionar". Así dice Jesús. Entonces ahí está: Jesús es individualista. Así es el Nuevo Testamento. Así es el griego también. Es sujeto-objeto y en el tojolabal no hay objeto. Jesús también es hermano y no objeto. Entonces el Nuevo Testamento es individualista. Nos quedamos en esa situación. Y me parece muy significativo, en situaciones de vida y muerte no solamente la tuya y la mía, lo que implica una mentira. Somos corresponsables de las vidas de los hermanos y hermanas. Podemos ver ahí que entre los tojolabales el grupo predomina. Por eso la forma rara de la frase: "Uno de ustedes me van a traicionar". Cada uno de los discípulos que quedan pregunta: “¿Seré yo?” Es decir, no sabían si en esa situación van o no van a traicionar. Y entonces podemos decir que, aunque Jesús en el texto no contesta, podría contestar: "Cuando llegue el minuto tú vas a saber si traicionarás o no traicionarás. No te voy a decir de antemano".

- Pero, ¿hay otras traducciones?

- Hay una traducción de un grupo protestante, evangélico. Se tradujo el Nuevo Testamento. Hay un texto en una de las tres cartas de Juan y dice: "Si cometemos un error o un pecado, algo por el estilo, tenemos un defensor, Jesucristo, bueno, Jesús”. La pregunta era, para la traductora, ¿cómo traducimos defensor?

La traductora pensó en su situación. Si estamos en problemas, ¿con quién vamos? Con el licenciado, un abogado, porque la palabra "licenciado" también existe en tojolabal. Bueno, así 
está en su traducción. Yo pregunté a algunos tojolabales: "Hermano, ¿dime qué entiendes por licenciado?”. "Licenciado, ¡ay!, te voy a decir: es un traidor. Es un explotador. Siempre quiere más dinero y no hace lo que le pedimos". Si traducimos otra lengua desde nuestra perspectiva, entonces fallamos.

Cualquier lengua que estudiamos y cualquier cultura tenemos que interpretarla desde la perspectiva de ellos. En Antropología hay las palabras EMIC y ETIC. EMIC es de la perspectiva de ellos, ETIC de la nuestra. A veces nos cuesta aceptar la perspectiva de ellos.

La inclusividad de la lengua se manifiesta también de otra manera. Al hablar de los padres o papás, no se menciona sólo la parte masculina de nuestros procreadores, sino que hay que decir: nuestras mamás nuestros papás (ja jnan jtatiki). Observamos dos cosas. No sólo nombramos a madre y padre, sino que las mujeres preceden. Por ello, los tojolabales decimos

mujeres y hombres ('ixuk winik)

muchachas y muchachos ('ak'ix kerem)

abuelas y abuelos (ja jme'xep jtatewoltiki)

etc.

Sabemos que en castellano se suele decir hombres y mujeres, muchachos y muchachas, abuelos y abuelas, etc. Es decir, los varones se mencionan en primer lugar.

Hay una excepción en tojolabal donde la relación se invierte. Cuando en español queremos hablar con cortesía y dirigimos la palabra a una reunión, decimos señoras y señores. Ahora sí son las mujeres que se mencionan en primer lugar. Nos referimos, por supuesto, a gente de una clase social distinguida o elevada. En este caso, los tojolablales solemos decir señores y señoras. Es decir, estamos invirtiendo el orden acostumbrado entre nosotros los tojolabales. La razón de este giro del lenguaje es la siguiente: en esa clase social las mujeres no tienen precedencia, no se las respeta como lo hacemos entre nosotros. Por eso, en 
Hechos 17:2 donde se habla de mujeres distinguidas y hombres invertimos el orden y traducimos señores y señoras ricas.

Ahora bien, sabemos y ya lo mencionamos que en la Biblia siempre se habla de nuestros padres sin mencionar a las madres. La traducción de la Biblia al tojolabal tiene que plegarse, por supuesto a la particularidad del idioma inclusivo. Por eso, la versión tojolabal del Nuevo Testamento no habla sólo de nuestros padres sino siempre de nuestras madres y padres (Lenkersdorf, "Hermanos lectores", 8-9).

- Ustedes tradujeron el Nuevo Testamento y cuentas de un pasaje que viene de los evangelios en donde se habla de "las viejas" y de su contradicción con la referencia de evangelio como "buena nueva".

- En un lugar de la Biblia estábamos traduciendo y en un pasaje los representantes de las comunidades comentaron: "Evangelio quiere decir 'buena noticia'. Para todos". Ahí llegamos a un texto ya avanzado. Comenzamos con Marcos como primer evangelio y así con los otros. Llegamos a un texto que escribe Pablo a Timoteo.

En otra ocasión en 1 Timoteo 4:7 se habla de cuentos de viejas. Esta expresión nos preocupa y molesta. ¿Cómo es posible que en la Biblia se habla con desprecio de personas de edad y de mujeres? Nosotros, los tojolabales, en nuestras comunidades mantenemos con firmeza el respeto a las personas ancianas. Lo expresamos en palabras y comportamiento. A las personas de edad se les llama ancianas o ancianos (me'jun o tatjun) para manifestar el honor que se les debe. Por eso, buscamos una expresión apta para "traducir" las palabras que nos preocuparon. Los traductores, pues, optamos por los cuentos que no sirven (ja lo'il jumasa' ja b'a mi xmakuni).

Vemos, pues, que la transformación del griego del Nuevo Testamento en lengua inclusiva tuvo que hacerse necesariamente, porque en tojolabal no podemos hablar de otra manera. En algunos casos mencionados exigimos el cambio, para mani- 
festar el evangelio con más claridad. Es decir, para que también sea Buena Nueva por ejemplo para mujeres ancianas. Lo estamos haciendo para obedecer al evangelio que, seguramente, no quiere que despreciemos ni a las mujeres ni a las personas de edad (Lenkersdorf, "Hermanos lectores", 10-11).

— "Nada de cuentos de viejas". Entonces los alumnos, o los traductores escuchábamos. “¿Qué dijo ahí el apóstol? Traduce, dilo otra vez". Y yo, traduciendo contesté: "No cuentos de viejas". Bueno, dijeron: "Eso no podemos traducir. Tú nos dijiste que evangelio es una 'buena nueva para todos'. Eso no es buena nueva para las señoras — no dicen señoras - para mujeres de edad". Y entonces hubo una larga discusión.

Entonces buscaron un camino que dijera "cuentos que no nos sirven". No tradujeron mecánicamente ni siguieron las reglas de cómo supuestamente se debe traducir sino algo que estuviera acorde a su cosmovisión. No sé cómo era Buber al traducir el Antiguo Testamento o la Biblia al alemán.

- La idea de él era justamente que el alemán se extrañe para escuchar la lengua hebrea. Por eso fue tan criticado. Dijo Kracauer que esa traducción le quitaba toda la virilidad al alemán; que era una traducción femenina.

- Es un problema la traducción, sí.

- Ya que estamos hablando del Antiguo Testamento, ¿cómo crees que se traduciría al tojolabal el pasaje de Caín y Abel y toda esta cuestión de la responsabilidad y todo lo que está ahí implicado?

- Bueno, esa pregunta va más allá de lo que puedo responderte. Entonces, lo siento. Ese pasaje no se usaba mucho que digamos. Lo que los tojolabales prefieren y saben y discutieron. Entre ellos lo que predomina es "Éxodo". ¿Por qué?

- ¿Por la esclavitud, por la liberación...?

- No. ¿A dónde va el pueblo de Israel?

- A la tierra prometida. 
— ¡Eso! Por eso. Es muy importante para ellos el texto del testamento. Llegamos y nuestro Dios quiere que lleguemos a la tierra prometida.

- Pero, ¿cómo traducir "Dios"?

- Lo voy a decir después del cuento. Don Samuel, el obispo, llegaba a las comunidades visitándolas por grupos. Rara vez visitaba una sola comunidad. Si hubiera sido así, no hubiera podido en un año ir a todas las comunidades. Son demasiadas para un año. Lo hizo por cañadas. Antes de la visita en la cañada a la cual me refiero, la comunidad le dijo a don Samuel: "No queremos que venga solamente para bautizar y casar. No. Tiene que venir por lo menos tres días. El primer día nosotros vamos a explicar 'Nuestra lucha' (y dijeron 'lucha'). El segundo, tú nos explicas dónde estás en nuestra lucha, de nuestro lado o del lado de los patrones. Y el tercer día podemos festejar, bailar, tú puedes bautizar, tú puedes oficiar matrimonios y todo eso y podemos estar alegres".

Entonces, cuando estaba preparando la visita entre otras cosas, de repente alguien dijo: “¿Cómo vamos a hablar al obispo? Dijimos hasta ahora ‘señor obispo' pero eso es español, señor. ¿Cómo traducimos? 'Señor' traducido quiere decir ajwal, patrón, mandón, etc. Bueno, por malo que sea el obispo, vamos a ver, pero no queremos que sea mandón, que sea ajwal. Pero ajwal también quiere decir otra cosa. Ajwal quiere decir Dios, nuestro Dios, kajwaltik. Pero por bueno que sea no puede ser Dios. Señor y ajwal no puede ser. Larga discusión. ¿Cómo vamos a llamarlo?

Para los tojolabales de hoy el término 'ajwal se refiere definitivamente a personajes masculinos que de alguna manera, $\mathrm{y}$ por lo general, se hicieron distinguidos o notorios, en el sentido negativo. El término puede traducirse por "señor" o "patrón". Al decir kajwal nos referimos a "mi patrón" o "mi señor". En la acepción de personajes destacados, a lo largo de la historia, el término ha pasado por un profundo cambio en los distintos 
idiomas mayas. En la época elitista del Clásico, más o menos del 300 al 900, los 'ajaw ocuparon las posiciones privilegiadas. Al terminar el periodo Clásico se acabaron estas posiciones. Por eso, entre los tojolabales de hoy, seguramente desde algunos tiempos atrás, no hay nadie a quien se llame 'ajwal o kajwal, porque se tiene una aversión contra los 'ajwal.

Es decir, entre los tojolabales nadie es señor y a nadie le llaman señor o señora, 'ixawal. Los tojolabales se llaman entre sí 'ermano, hermano, winik, hombre, 'ixuk, mujer, moj'aljela, hermano, kumpare, compadre, kumare, comadre, tata, tata, nana, nana, tatjun, anciano, me'jun, anciana, etc. Todas estas formas de tratamiento no señalan ninguna diferencia de posición social, sino que reflejan que los tojolablaes se consideran iguales entre sí. Los términos mencionados indican diferentes funciones dentro de la sociedad, pero ninguna estratificación social. Al referirse a tatjun y me'jun se expresa el respeto particular que se tiene frente a las personas de edad.

Las personas de edad, por muy respetadas que sean, por la experiencia acumulada a lo largo de muchos años no tienen el derecho de mandar. A los seres celestiales los tratan también de jwawtik-jnantik, nuestro papá grande, nuestra mamá, que corresponden más o menos al sol y la luna. Es decir, forman parte de la familia cósmica de iguales y, a la vez, merecedores de mucho respeto por las funciones que desempeñan.

Con la llegada del cristianismo y de los europeos se introdujeron jerarquías sociales. Los españoles, por supuesto, fueron los "señores y señoras" y así también a Dios se le asignó el nombre de kajwaltik, Nuestro Señor. Es decir, la sociedad colonial, con los niveles sociales y religiosos, introdujo diferencias de posición social y de esta manera se distinguían la sociedad de los colonizadores y la de los colonizados, de españoles y de indios (Lenkersdorf, "Señor — 'ajwal”, Conceptos, 192-193).

- Ahí otra vez, la traducción. Finalmente llegaron a la palabra española "hermano". Es hermano obispo, como hermano, todos somos hermanos. A mí me llaman hermano. Todos somos hermanos y hermanas, iguales. El obispo también. Entonces es 
hermano y obispo. Obispo es su función. Nuestra función es campesino, podemos decir milpero, etc. Así, cada uno de nosotros tiene su función pero socialmente somos iguales y el obispo, tú también eres hermano. Tu función es, sabemos, bautizar, matrimoniar, aconsejar, etc., pero eres hermano y por eso "hermano obispo".

- ¿Hermano es semejante?

- Sí, puede ser semejante pero es igual.

- Pero no es la idea tan criticada occidental de que hermanos somos los que tenemos una comunidad de intereses y que defendemos lo nuestro contra el otro. Como un pacto.

- No, eso no. Se es su hermano cuando vas a trabajar con ellos. Resulta interesante explicar cómo se llega a ser tojolabal. No se da por el hecho de que tú naces en una familia tojolabal o en una comunidad tojolabal. Siempre hay traicioneros, siempre hay "judas". Es decir, no nacemos tojolabal sino que nos hacemos tojolabales. Al integrarnos y aceptar, digamos, la cosmovisión o la comunidad e integrarnos a la comunidad, en ese momento se llega a ser tojolabal. Es un proceso.

Las tortillas pueden estar en situaciones diferentes, por ejemplo, k'unil waj, tortilla suave, takin waj, tortilla seca, etc. Un tojol waj expresa con claridad el concepto de tojol que encontramos con referencia al idioma y el pueblo que lo habla. El tojol waj es la tortilla caliente y suave en el momento que sale del comal, que llena la cocina con su perfume y que provoca que se haga agua nuestra boca. Dicho de otro modo, es la tortilla en su punto, como dicen los comitecos; es la tortilla que cumple con su "vocación". Así, sirve de explicativo para los demás usos del concepto tojol. El tojolabal, por tanto es la persona que cumple con su vocación aquí y ahora; sabe escuchar y no se impone (Lenkersdorf, “Tojol”, Conceptos, 202).

- Tojol originalmente quiere decir derecho como un pino o una cosa así derecha. La tortilla es tojol no por estar derechita, 
sino porque está en su punto, porque cumple con su vocación. Y el tojolabal cumple con su función. Por eso se llama tojol'abal, cuando sabe escuchar y no solamente habla por hablar. Ahí la diferencia y otra vez lo interesante es que se llama a sí mismo tojol y 'abal para que sepa escuchar y no kumal, que sepan escuchar cualquier habla. Decimos que existen los medios de "comunicación" pero ahí no se comunican. En ellos solo hay una dirección en el habla. No hay escucha.

En español decimos "Yo te digo". Bueno, pongamos el caso de un militar. En ese medio, la frase "Yo te digo" tiene implícito que el subalterno tiene que obedecer. Si no sigue la orden sabe lo que pasará. La frase correspondiente [en tojolabal] a "Yo te digo" es "Yo digo. Tú escuchas". No hay objeto indirecto. El decir ya está implícita la pregunta por tu opinión. Porque escuchaste, entonces tú vas a hablar y decirme qué piensas. Como digo en clase. Si me critican, ese es el propósito, que nos entendamos mutuamente. Entonces, somos iguales. Yo hablo, tú escuchas. También Samuel quiere escuchar y no solamente hablar, sea en el púlpito o donde sea, en la comunidad. La idea es que nos platiquemos entre nosotros.

Los tojolabales tienen palabras españolas para aquellas que no tenían palabras en tojolabal. Así para rico, pobre, no hay palabra. Se puede decir "Tiene mucho dinero", pero sin rico y pobre. También enemigo. Fíjate, verdad, una sociedad que no tiene enemigo.

En otras ocasiones tradujimos conforme al texto original que sí, a veces, nos causó extrañeza. Por ejemplo, se acepta la esclavitud (1 Corintios 7:21s; Efesios 6:5-7; Colosenses 3,22-23; etc.). Para nosotros la esclavitud, en forma del baldio, es una experiencia muy amarga que terminó hace apenas cincuenta años. La memoria sigue viva porque nuestras abuelas y abuelos nos cuentan de su juventud de "baldiyanos" o esclavos. ${ }^{8}$ En el

${ }^{8}$ Véase Gómez y Ruz, Memoria Baldía. 
contexto de esta historia tojolabal, no olvidada hasta la fecha, el testimonio de Moisés y de la labor liberadora de Yavé en Egipto expresa la Buena Nueva con mayor claridad que las palabras apostólicas mencionadas. La lectura de pasajes bíblicos de esta clase seguramente producirá el "conocimiento crítico" de la tradición cristiana de parte de una cultura no occidental, queremos decir Maya como es la nuestra. Por ello, la oposición vivida a la esclavitud, muy presente en todo nuestro pueblo, puede sentirse más cerca de la voluntad del evangelio que las palabras del escritor neotestamentario. Así se podrá fomentar el aprecio mutuo de dos culturas bien distintas en el sentido de que en ocasiones Dios habla más claro a los unos que a los otros y que todos tenemos que aprender los unos de los otros. ¿No les parece así también? (Lenkersdorf, "Hermanos lectores", 11-12).

- ¿Y cómo le hicieron para traducir esas palabras de la Biblia como castigo, enemigo?

- Sí, todas las palabras: castigo, cárcel, juez. Todo viene del español. No había en su lengua hasta la fecha. No hay juez. Entonces yo estaba con los indígenas que viven al otro lado de la frontera, los kanjobales. Me invitaron a un proceso judicial y era entonces el acusado o el delincuente un hombre casado con mujer. No me acuerdo si tenía hijos. Posiblemente. Violó a una muchacha. Entonces había ese proceso. Y al hablar ahí dijeron, el kanjobal lo entiendo más o menos: "No queremos la justicia de ellos, con jueces de ellos, con castigos de ellos, con tortura de ellos, y así todo eso, sino la justicia nuestra que no es condenar sino reeducar". Le hablaban al delincuente emotivamente. Seguían diciéndole "hermano". Era el tiempo de la guerra civil y él era cartero, llevando mensajes de una comunidad a otra. Era importante que no encontraran el mensaje en caso de que quedara detenido. "Eso te dimos porque tuvimos confianza en ti y ahora abusaste de la confianza, y violar una muchacha". Le quitaron el trabajo de cartero. Entonces le dijeron: "Nos vamos 
a fijar, poner ojo en ti, por tanto tiempo, pero no un castigo. Pero nos fijamos, para que te reintegres como un hermano debe portarse en la comunidad". Eso yo vi también con los tojolabales.

A veces, se manifiestan cosas importantes por la ausencia de palabras correspondientes a aquellas que son tan comunes en el contexto indoeuropeo, incluso el bíblico. Por ejemplo para traducir la palabra "enemigo" empelamos una palabra derivada del español (se dice kronta derivada de contra). ${ }^{9}$ Rigoberta Menchú nos dice algo más en cuanto a la ausencia de esa palabra, tan importante en el contexto indoeuropeo (Lenkersdorf, "Hermanos lectores", 12).

Empezamos a emplear el término enemigos. Porque en nuestra cultura no existe un enemigo [;] como el punto a que han llegado esa gente con nosotros, de explotarnos, de oprimirnos, de discriminarnos; sino que para nosotros, en la comunidad, todos somos iguales. [...] así fue cuando [...] me dije, tenemos que derrotar al enemigo (Burgos, Me llamo Rigoberta, 149).

- Hay un ejemplo que Gudrun, mi esposa, me contó. Estaba en un bautizo y después del bautizo el sacerdote preguntó a la mujer: "Ahora, a tu hijo bautizado, cómo vas a educarlo". La mujer, una sola palabra: "Respeto". Ahí tienes palabras tojolabales, cómo traducir, cómo te vas a cambiar para estar a tu punto, escuchar, respetar.

- La palabra venganza, ¿no tiene traducción?

- Bueno, por el momento, "portarse mal". Tal vez tienen la palabra "venganza" que usan del español. Son ejemplos de cómo traducir una lengua a la otra siempre desde la perspectiva de ella.

${ }^{9}$ La ausencia de la misma palabra notamos en los idiomas de pueblos vecinos, por ejemplo los tzotziles y tzeltales, como los diccionarios correspondientes lo corroboran. 
Tampoco hay palabra para "dinero", ídolo por excelencia en los evangelios y otras partes de la Biblia. Para Jesús el dinero es aquello que se opone a Dios (Mateo 6,24). En tojolabal, en cambio, dinero se traduce por metal (tak'in) como cualquier cosa hecha de metal, sea adorno sea herramienta. ¿No es un recuerdo de los tiempos precolombinos cuando las sociedades autóctonas no tenían dinero fuera de la semilla del cacao? Es decir, dinero no metálico que no dura, sino que se pudre en el curso de un año. ¡Imaginémonos el Banco Mundial y el Fondo Monetario Internacional con esa clase de dinero! Al terminar cada ciclo agrícola se acabará todo el dinero amontonado. Se borran todos los estados de cuenta. Se acaban todos los debes o deudas. En aquel entonces, pues, no tuvo sentido de hablar de gente que tenga metal para referirse a los ricos. Por ello nos toca enfocar el problema del "rico".

En tojolabal no hubo palabra para rico ni para pobre. Hoy día, sí se están usando las mismas palabras prestadas del español. Si, en cambio, queremos hablar de un idioma más puro, decimos para rico el que tiene metal (dinero) [ja ma' ay stak'in] y para pobre el que no tiene metal [ja ma' mey stak'in]. Expresamos, pues, la riqueza en nuestro idioma conforme al modo o criterio de la cultura occidental-acumulativa. Ahora bien, si hablamos del evangelio, vemos que tienen que inculturarse en nuestra cultura que, por sus raíces, desconoce la idolatría, tan arraigada en al cultura occidental, de adorar las riquezas, de acumular cosas y de cuantificarlas. Por supuesto, hoy día la influencia de la sociedad acumulativa y dominante ha dejado sus huellas en la sociedad tojolabal. No ha logrado, sin embargo, convertirla en sociedad que corre tras la riqueza. Dicho de otro modo, ¿no es que al traducir el evangelio lo estamos incorporando a una cultura mucho más idónea para la Buena Nueva que la cultura occidental a la cual, hasta la fecha, se le suele considerar cristiana?

Otra vez estamos haciendo una observación instructiva. La lectura reflexionada y crítica de las culturas nos deja ver diferencias culturales profundas que nos enseñan también distintas estructuras sociales: una sociedad es acumulativa y así cuantifi- 
ca las cosas mediante el dinero; la otra, en cambio no tiene estas características. El juicio evangélico sobre las dos es obvio. Sólo en el contexto de sociedades y culturas acumulativas caben las historias del becerro de oro o del rey Midas con la facultad de trocar en oro cuanto tocaba. En la cultura tojolabal, en cambio, a las mujeres y hombres no las definimos por lo que tengan. ${ }^{10}$

Dicho de otro modo, ¿dónde encontramos las famosas "semillas del Verbo" concedidas por la Iglesia a las culturas no convertidas al cristianismo? ¿No conviene decir con humildad que en el contexto occidental muchas semillas sembradas, ya hace casi dos mil años, se han quedado muy raquíticas? Entre los tojolabales, en cambio, encontramos frutos maduros, porque hasta la fecha no nos hemos entregado a la adoración idolátrica del becerro de oro. En cuanto al enemigo, sí tuvimos que aprender esa realidad de los cristianos. Decimos estas cosas no para presumir de listos sino para afirmar otro asunto. Así como aprendimos de los no-indios y no lo negamos, queremos preguntar si no tenemos algo que ofrecer que los no-tojolabales pueden aprender de nosotros. ¿No es conforme al evangelio que aprendamos los unos de los otros? Pensamos que sí tenemos cosas que enseñar para el bien de nuestros hermanos noindios (Burgos, Me llamo Rigoberta, 13-15).

- Desde la perspectiva de la justicia que repara, que educa. - Sí, ahí también. Hay palabra para bueno, es lek. Leki l’ixuk leki winik. Son una mujer del lado bueno, que sabe cumplir con respeto, etc. Pero no hay palabra para mal. Entonces dicen "mal". Pero no hay palabra. No vivimos en la alternativa entre bien y el mal. ¡Quién sabe cuántas cosas, novelas y filosofía entre el bien y el mal!

- Hay una lógica muy distinta de la oposición y del tercero excluido.

${ }^{10}$ Tampoco podemos hacerlo por lo que son, ya que ni siquiera hay el verbo ser. Por falta de espacio, aquí no podemos entrar con detalle en este aspecto de la cultura y lengua tojolabal. 
- Una lógica muy distinta. Pero se puede comparar la intersubjetividad con el nosotros. Aunque usé la palabra intersubjetividad que puede estar ligada a Husserl, decidí cambiarla por el nosotros entre los tojolabales. Una vez en la clase cuando hablé de dos lógicas un alumno me dijo: "No, eso no hay. La lógica es una y universal".

- Teníamos otra pregunta. Cuando se hizo la traducción al tojolabal ¿cómo hacer compatibles dos visiones: una muy monoteísta y otra desde lo que platicábamos de una visión nosótrica y cómo hacer ver la cuestión de Dios con por ejemplo, jnantik luum, nuestra madre tierra? ¿Fue difícil?

- Sí, los tojolabales son católicos pero ya no todos. Muchos se hicieron protestantes. Fue con los católicos con quienes tradujimos y con quienes trabajamos mucho tiempo, diez años. No, más, treinta.

Un día, una muchacha joven católica monoteísta le dijo a mi esposa, todo en tojolabal: “¿Sabes qué? Ahora nos quieren enseñar que todo este mundo fue hecho por uno solo. ¿Quién puede creer esos cuentitos?".

Afirmamos de un modo algo tajante que los tojolabales nos identificamos por la comunidad de consenso a la cual pertenecemos, que nos da la posibilidad de vivir y a la cual mantenemos por todo lo que estamos haciendo. De ahí la importancia de la palabra y de la realidad del nosotros en tojolabal. No sólo hay dos formas lingüísticas de nosotros, sino que la comunidad, representante de ese nosotros, no se refiere sólo a la comunidad particular donde cada uno nació, sino que puede extenderse a todo lo que tenga corazón. Y no hay nada que no lo tenga. Por ello vive y, por eso, también es hijo de la madre que es mamá de todos: Nuestra Madre Tierra (ja jnantik lu'um). La convivencia, pues, con todos aquellos que tengan corazón, todos los hijos de la Madre Tierra, es decir con todos nuestros hermanos nos identifica a nosotros. Vemos que la comunidad de consenso puede alcanzar dimensión cósmica (Burgos, Me llamo Rigoberta, 15-16). 
- Cuando estás rascando un poquito está presente su tojolabalidad prehispánica.

- Sí, pero rasca otro poquito ahí en la Biblia, y Elohim es plural.

- Ahí está. En el primer versículo ya...

- Y ahí los tienes a muchos.

- Bereshit bará elohim... (Y en el comienzo creó [aron] $\operatorname{dios}[\mathrm{es}])$.

- Si hubiera dicho Hael, no habría problema. Pero el problema está en la lógica, justamente en esta lógica única que antes criticaste. Es el problema de la identidad. Porque nosotros entendemos la identidad como uno. Para ellos la identidad es colectiva.

- Claro, se ve también en el Popol Vuh. Hay un problema. La palabra "Dios" no existe. Entonces tradujeron como formadores y creadores, comparando Génesis: "Hágase la luz y se hizo la luz" como encender un apagador. Para ellos hay una reunión: ¿Cómo vamos a hacer los hombres?

Entonces los primeros hombres, de tierra, de barro. Pero los de barro se derritieron. Allá, los creadores y formadores. Como los tojolabales, otra asamblea. Se reunieron. Segunda generación: de madera. Entonces no se derritieron pero se pusieron muy prepotentes. Se olvidaron de sus creadores y formadores, uno de los delitos más fuertes entre los tojolabales y también entre los mayas. Entonces, realizaron otra asamblea y dijeron: "Fallamos otra vez. Se hicieron prepotentes. Se olvidaron de nosotros. Entonces, vamos a destruirlos”. ¿Cómo los destruyen? Les hablaron a los comales y a los animales (donde estaban moliendo el maíz) ${ }^{11}$ porque todo vive: "Ustedes nunca nos respetaron y los vamos a destruir". Fin de la segunda generación. Otra asamblea.

${ }^{11}$ Hay al parecer una inconsistencia en el Popol Vuh porque si no habían encontrado todavía el maíz para hacer a los seres humanos, de dónde salió el maíz. Esto no es explicado. 
En la tercera asamblea hubo inconsistencia. Entonces aparece la abuela. “CCómo hacer a los hombres?" "De maíz”. De debajo de las rocas, lo cuidaban las hormigas. Fundieron maíz y sangre para hacer a los hombres del maíz. ¿Cómo llegaron a ser humanos? Con el respeto. Ahí nos volvemos humanos.

La palabra wawal es una palabra multifacética. En el contexto religioso puede referirse a personajes que merecen sumo respeto o a quienes se rinde reverencia y veneración. La referencia puede ser a Dios, llamado el Santo, pero se hace de un modo particular. En el contexto bíblico el Santo es sagrado y, por tanto, apartado del mundo humano y profano. Por eso se exigió a Moisés que se quitara las sandalias, porque estuvo pisando tierra sagrada (Éxodo 3, 5). Los tojolabales convierten al Santo en un anciano, un padre respetado y querido y, como tal, no apartado, sino que pertenece al mundo comunitario o nosótrico de los tojolabales. Para ensalzarlo se agrega: "tú eres nuestra cabeza en el mundo", "tú eres el verdadero wawal/padre, Señor nuestro" (Apocalipsis 6:10 y 3:7). Se mezclan elementos tojolabales y cristianos. El traslado del Santo a la comunidad tojolabal se ve, finalmente, al referirse a los santos y santas que en tojolabal se llaman jnantik, nuestras madres, y tatik, nuestros padres, dentro de los cuales se encuentran el jtatik jesus, nuestro padre Jesús, el jtatik pagre'eterno, nuestro Padre Eterno (el santo de Trinitaria o Zapaluta, a $16 \mathrm{~km}$ de Comitán hacia la frontera con Guatemala) y también jnantik walalupe, nuestra Madre Guadalupe, y jnantik lu'um, nuestra Madre Tierra. Con referencia a esta última, sin embargo, se hizo el comentario: "pero ella vive, está en medio de nosotros" (Lenkersdorf, "Religión", Conceptos, 181).

- Por eso no hay contradicción entre ja jnantik luum, nuestra madre tierra y tatik Jesús nuestro padre Jesús. Los tojolabales tienen muchos papás y mamás. Tenemos muchos padres y muchas madres, como jnantik Guadalupe, o jnantik María, pero es la tierra, ja jnan tik luum, Nuestra Madre Tierra, la que está con nosotros y siempre nos acompaña. 
En estos pocos rasgos escogidos podemos comenzar a captar las semillas o el armazón de lo que llaman nuestra cosmovisión. No es nada de teoría, de puras palabras, sino que es aquello que vivimos, hacemos y practicamos. Lo importante no son tanto las palabras sino saber convivir con todos los demás. Las palabras que nos dicen pueden ser muy bonitas. De hecho, muchas, muchas veces nos las decían. Así nos platicaron padres, maestros, médicos, agrónomos, políticos y tantos peritos más. Nos dijeron palabras bien bonitas, pero sólo palabras que tantas veces se quedaron lejos de transformarse en hechos. Para nosotros, los tojolabales, en cambio, la palabra sí cuenta siempre que se cumpla, que se ponga en práctica. ¿No estamos siguiendo la Palabra de Dios, si los hechos nos importan más que las palabras? Porque así captamos las palabras de Jesucristo que tradujimos "no entrarán en el Reino de Dios los que me digan Señor, Señor, sino los que hagan las cosas que dice mi Padre que está en el cielo" (Mateo 7:21) (Lenkersdorf, "Hermanos lectores", 16).

- Volviendo a la traducción, a estos 70 del Otro. Cabría citar el agradecimiento, que posiblemente sea único en una Biblia:

Ahora bien, la traducción representa nuestro proyecto. No cobramos, ni se nos pagó. La impresión, en cambio, no se puede llevar a cabo sin "metal" que aquí no se encuentra entre nosotros. Por eso, llegó la ayuda solidaria y oportuna del extranjero.

Tal vez no habría sido necesaria, si existiera en el mercado internacional un precio justo por el café producido y vendido por algunas comunidades nuestras. De hecho, se nos informó que los campesinos tercermundistas que lo producen reciben sólo el 8 por ciento de lo que paga el consumidor en el primer mundo. [...] Lo mencionamos para hacerles ver, a ustedes y también a nosotros, que la Biblia, por espiritual que sea, está relacionada con el café y el mercado internacional y así también el trabajo productivo de nosotros, campesinos tojolabales (Lenkersdorf, "Hermanos lectores", 17). 


\section{Epílogo}

Agradecer, es lo que queda, esta lección que a través de Carlos Lenkersdorf nos llega de parte de los tojolabales. Se trata del espejo que solo el Otro es capaz de ofrecernos para descubrir un rostro oculto de nuestro "Occidente".

Traducir, según Walter Benjamin ("Tarea del traductor”, 214), es dejarse estremecer por la lógica del otro. Así los Evangelios descubrieron otras facetas de sí mismos a través de esta otra traducción. Es inevitable comparar esta traducción con la que, en el siglo III a.C. emprendieron 72 ancianos en Alejandría y que se conoce como Septuaginta o LXX. La leyenda narra que, siguiendo la orden de Ptolomeo II Filadelfo, se encargó esta labor a 72 sabios que, incomunicados, llevaron a cabo la tarea de trasladar el texto del hebreo al griego. La sorpresa fue descubrir la univocidad del resultado: una única e idéntica versión, repetida setenta y dos veces. Occidente privilegia la lógica unitaria del Mismo, el mérito individual y esta leyenda encarna ese ideal de identidad excluyente.

Los 70 tojolabales, por su parte, constituyen el reverso de esta historia. Si bien se trata también de un acto de traducción, esta vez de los Evangelios, el trabajo se rigió por la lógica de la pluralidad y la construcción del consenso. Veintitrés siglos más tarde, en las comunidades tojolabales de Chiapas, el texto base del cristianismo encontró interés justamente en aquellas partes que no eran las que la lectura en lenguas modernas "occidentales" privilegió.

Comúnmente la traducción se entiende como un trabajo solitario. En el mundo globalizado, los traductores consultan sus dudas por internet pidiendo asesoría a otros especialistas, decidiendo finalmente según un criterio personal. Existen equipos de traductores y cierta idea de colaboración. El modelo sigue siendo individualista. ${ }^{12}$ A diferencia de este individualismo, el

\footnotetext{
${ }^{12}$ Parafraseando a Martin Buber (él se refiere al nacionalismo) que el "trabajo de
} 
colectivismo tojolabal revela que la traducción no escapa a la dimensión política y que la discusión que tiene lugar en una democracia directa apuntando a un consenso puede abrir otro horizonte a la manera de dejarse enseñar (objetivo principal que conduce a traducir el texto bíblico a cualquier lengua). Sin duda para llevar a cabo una tarea semejante hay que renunciar a la pulsión de inmediatez que exige nuestro mundo mediático, pero el resultado es una experiencia democrática sólida que transforma a la lectura en un acto de escucha sensible a la polifonía. Se podría oponer a la noción griega de orthos (que significa recto, correcto) el vocablo tojol mencionado en la entrevista, que alude a la suavidad curva de estar "en su punto". Esta distinción parece prometer que la versión tojolabal del texto bíblico sería inmune a la ortodoxia.

Si bien la traducción de la Biblia al tojolabal cumplió con la intención inicial de evangelización, por causa del método deliberativo-cooperativo se produjo a contrapelo un sacudimiento de los Evangelios que los confrontó a sus intenciones originales frecuentemente olvidadas. De esta manera, el tojolabal le pudo enseñar al griego algo que Grecia (y Roma también), sin saberlo, a través del texto, transmitió: una sabiduría del Otro que estaba tan profundamente encarnada en el Evangelio, y que las lecturas superficiales olvidaron. Por esta razón, la versión tojolabal sorprende al lector distraído al recordarle que la producción del café concierne de manera radical al texto más espiritual de Occidente y por eso mismo invita a otra experiencia, ética (y también política), de lectura.

equipo" tan recomendado en nuestros días tiene más de "egoísmo colectivo" (ya no en defensa de la nación sino de un proyecto, una empresa, etc.) que de cooperativo. 


\section{REFERENCIAS}

Burgos, Elisabeth, Me llamo Rigoberta Menchú y así me nació la conciencia, México, Siglo XXI, 1985.

Benjamin, Walter, "La tarea del traductor", en Ensayos escogidos, México, Ediciones Coyoacán, 2008.

Gómez Hernández, Antonio y Mario Humberto Ruz, Memoria Baldía. Los tojolabales y las fincas. Testimonios, México, Universidad Nacional Autónoma de México, 1992.

LENKERSDORF, Carlos (ed.), "Hermanos lectores no tojolabales", en Ja yajk'alchil sju'unil ja dyosi (El Nuevo Testamento en tojolabal, vol. 2), Comitán, La Castalia, 1993.

Lenkersdorf, Carlos, Filosofar en clave tojolabal, México, Miguel Ángel Porrúa, 2002 (Filosofar de nuestra América).

LenKersdorf, Carlos, Conceptos tojolabales de filosofía y altermundo, México, Plaza y Valdés, 2004.

LENKERSDORF, Carlos, Aprender a escuchar. Enseñanzas maya-tojolabales, México, Plaza y Valdés, 2008.

The Greek New Testament (El Nuevo Testamento Griego), Kart Aland et al. (eds.), Stuttgart, Sociedad Bíblica Alemana, 3ª ed., 1983. 